\title{
PERBEDAAN INFORMASI ANATOMI \\ SEKUEN T1WI FSE DENGAN FAT SATURASI DAN TANPA FAT SATURASI PADA PEMERIKSAAN MRI KEPALA IRISAN AXIAL POST MEDIA KONTRAS
}

\author{
DIFFERENCES IN ANATOMY INFORMATION \\ T1WI FSE SEQUENCES WITH FAT SATURATION AND WITHOUT FAT \\ SATURATION MRI EXAMINATION OF THE HEAD SLICE AXIAL \\ POST CONTRAST MEDIA
}

\author{
Dwi Kristiyanto ${ }^{1)}$ M Irwan Katili ${ }^{2)}$ Emi Murniati $^{3 \text { ) }}$ \\ ${ }^{1}$ RSUP dr. Soeradji Tirtonegoro Klaten \\ ${ }^{2,3,)}$ Health Polytechnics of Semarang-Indonesia \\ Email : dkristiyanto6@gmail.com
}

\begin{abstract}
Background: MRI of head post contrast media T1WI with Fat saturation the lesions appear bright whereas the organs around the fat looks darker. The purpose of this study was determine the difference in anatomical information of MRI Head FSE sequences T1 weighted axial slice using fat saturation and without fat saturation.

Methods: This research is a quantitative research to determine differences in anatomical MRI information head with FSE sequences T1 weighted axial slice using Fat Fat Saturation Saturation and without air MRI on 1.5 T. The results are summarized and described to determine the value of anatomic information. Then proceed with the Wilcoxon test to see differences in anatomical information on T1 weighted MRI with Chief FSE And without Fat Fat Saturation Saturation.

Result : The results obtained results description clearer criteria on the use of Fat Saturation is a pathological lesions without Fat Saturation is the maxillary sinus, orbit, skull base, CSF, Sulcus gyrus, cutis and sub cutis. For the p value is 0.108 (p>0.05) there was no significant difference MRI anatomical information chief weighted FSE T1 sequence axial pieces with Fat Saturation and without Fat Saturation

Conclusion : : From the analysis of quantitative seen that there are no differences in the anatomy of the head of information at the head MRI examination ( $p>0.05)$ between Fat saturation and Non Fat Saturation.
\end{abstract}

Keywords : Fat Saturation, Information Anatomy, MRI of the head

\section{PENDAHULUAN}

Kepala merupakan bagian yang terdiri dari cerebrum, cerebellum, tulang tengkorak, sinus paranasal dan orbita. Dalam kepala organ - organ di dalamnya adalah jaringan lunak dan lemak. Kepala merupakan tempat dari sistem syaraf pusat yang sangat penting untuk fungsi dari organ lainnya. Pada kepala sering terjadi kelainan kelainan seperti adanya massa maupun metastase atau keganasan. Sehingga apabila ada kelainan pada kepala akan mengganggu kinerja organ lainnya (Dharmaperwira, 2004).

Dalam bidang radiodiagnostik dan imajing yang ada pada saat ini memberi kemudahan bagi para praktisi kedokteran untuk mendiagnosa penyakit serta menentukan jenis pengobatan bagi pasien. Salah satu bentuk kemajuan tersebut adalah penggunaan alat MRI (Magnetic Resonance Imaging) untuk melakukan pencitraan diagnosa penyakit pasien (Margiono,2013).

Menurut Sunardi (2006), MRI (Magnetic Resonance Imaging) merupakan suatu alat diagnostik mutakhir untuk memeriksa dan mendeteksi tubuh dengan menggunakan medan magnet yang besar dan gelombang frekuensi radio, tanpa operasi, penggunaan sinar $\mathrm{X}$, ataupun bahan radioaktif. MRI digunakan untuk pemeriksan klinis mulai tahun 1982 dan digunakan pada pemeriksaan sistem saraf. Pada saat ini MRI terus berkembang dan banyak berperan dalam berbagai pemeriksaan baik untuk kasus cephalgia, tumor, metastasis, vertigo dan masih banyak lagi. Menurut Westbrook (1999), sekuens yang digunakan pada pemeriksaan MRI kepala meliputi sekuens $T 1$ spin echo sagital, T1 spin echo axial, TI gradien echo 3D, T2 fast spin echo axial, T2 fast spin echo coronal serta T2 fast spin echo 3D

Menurut Westbrook (1999), Fat Saturation merupakan salah satu teknik Fat Supression. Pulsa fat suppression hanya digunakan jika diaplikasikan pada jaringan (khususnya lemak), dan tidak efektif jika diaplikasikan pada udara. Fat Saturation direkomendasikan untuk menekan sinyal dalam jumlah yang besar dari lemak dan akuisisinya dapat dibuktikan pada citra enhancement media kontras. Fat Saturation juga bermanfaat untuk menghindari terjadinya misregistration artefak, sehingga dapat digunakan dalam berbagai macam imaging sekuen.

Pada pemeriksaan dengan kasus metastasis, khususnya yang mengenai kepala dilakukan dengan short TI Inversion recovery (STIR) atau pembobotan $\mathrm{T} 2$ fat suppresi maupun menggunakan media kontras dengan pembobotan T1 (Brant Zawadzki,2002). Media kontras yang dipergunakan dalam MRI adalah gadolinium (Gd) yang merupakan substansi paramagnetik yang mempunyai moment magnet yang cukup besar yang disenyawakan dengan diethylene triamine 
pentaacetic acid (DTPA) agar tidak berbahaya dan mudah diekskresikan dari dalam tubuh (Westbrook,2002). Menurut Siemens (2013) Fat Sat bekerja baik setelah pemasukkan media kontras gadolinium (Gd ).

Pemakaian media kontras Gadolinium (Gd) pada pemeriksaan MRI berfungsi untuk mengevaluasi kelainan kelainan baik itu tumor, inflamasi maupun infeksi. Media kontras Gd DTPA akan memperpendek waktu relaksasi T1 proton hidrogen pada jaringan, sehingga akan meningkatkan intensitas sinyal pada pembobotan T1 yang mengakibatkan enhancement terutama pada jaringan yang bersifat patologis. Oleh karena itu, gadolinium disebut dengan T1 enhancement agent (Westbrook, 2002).

Biasanya pembobotan $\mathrm{T} 1$ digunakan pada pembobotan setelah media kontras. Gadolinium digunakan dengan fat Suppresion untuk menekan fat marrow sehingga dapat menampakkan lesi enhancement (Westbrook,2002).

Fat Saturasi yang digunakan dalam pembobotan T1 post media kontras menghasilkan gambaran lemak yang tersuppresi sehingga citra anatomi disekitar lemak menjadi lebih gelap. Sedangkan pembobotan T1 tanpa menggunakan Fat saturasi menghasilkan citra anatomi disekitar lemak lebih terang (Al Saeed,2011).

Berdasarkan pengamatan penulis, di Rumah Sakit Dr Soetomo Surabaya Dan Rumah Sakit JIH Yogyakarta, pemeriksaan MRI kepala post media kontras hanya menggunakan sekuen T1 WI tanpa Fat saturasi sedangkan di instalasi radiologi RS Panti Rapih Yogyakarta menggunakan sekuen T1 WI FSE dengan fat saturasi namun dalam beberapa kasus tidak menggunakan Fat saturasi, dalam hal ini berbeda dengan yang disampaikan Zawadzki (2002) dalam pemilihan sekuens post kontras T1 biasanya tidak memakai fat Saturasi, sedangkan menurut Sirin (2012) dalam pemilihan sekuens post kontras T1 menggunakan kombinasi antara fat saturasi dan tanpa Fat saturasi. Pada pemeriksaan kepala post kontras gd dengan fat saturation di Rumah Sakit ini digunakan untuk mengurangi enhancement dari lemak yang terdapat di daerah basis cranii dan orbita. Potongan yang digunakan di dalam pemeriksaan kepala post kontras menggunakan potongan axial, coronal, sagital dengan fat saturasi, hal ini berbeda dengan yang disampaikan Al Saeed (2011) yang menggunakan potongan axial dengan kombinasi fat saturasi dan tanpa fat saturasi.

\section{METODE}

\section{Rancangan Penelitian}

Jenis penelitian ini adalah kuantitatif dengan pendekatan eksperimen, lokasi penelitian pada Instalasi Radiologi RS Panti Rapih Yogyakarta.

\section{Populasi dan sampel}

Populasi penelitan adalah semua MRI kepala. Jumlah sampel yang digunakan sebanyak 10 orang sampel, penentuan sampel dengan menggunakan teknik purposive sampling. Pengambilan data dengan kriteria tertentu seperti rentang usia $20-60$ tahun, pasien dengan injeksi media kontras. Tiga orang dokter radiolog sebagai responden. Hasil citra dinilai oleh responden dengan menggunakan kuisioner.

\section{Prosedur pemeriksaan}

Pemeriksaan MRI Kepala dilakukan pemeriksaan rutin sesuai dengan Prosedur yang diterapkan pada Rumah Sakit Panti Rapih Yogyakarta. Prosedur dimulai dengan melakukan perjanjian sebelum pemeriksaan, kemudian mengisi lembar prescreening pemeriksaan MRI, radiografer memberikan anjuran bagi pasien untuk buag air sebelum dilakukan pemeriksaan. Pasien diinstruksikan untuk mengenakan baju pasien dan melepaskan benda-benda yang mengandung logam seperti gigi palsu, anting, dan jepitan rambut, mengukur berat badan pasien,radiografer memberikan penjelasan kepada pasien bahwa pemeriksaan MRI membutuhkan waktu yang lama, menimbulkan suara bising, dan organ yang diperiksa tidak boleh bergerak selama pemeriksaan. Dilanjutkan dengan registrasi pasien mengisi data pasien, meliputi nama, umur, jenis kelamin, berat badan, nomor register, jenis pemeriksaan.

\section{Pengaturan posisi}

Memposisikan pasien supine diatas meja pemeriksaan dengan head first dan bagian kepala diberi Head coil.Posisi tubuh pasien diatur senyaman mungkin,dipastikan tidak ada rotasi, Mid Sagital Plane (MSP) tegak lurus meja pemeriksaan dan sejajar dengan lampu indikator longitudinal.Center point lampu kolimator dipusatkan pada regio inter pupilari Line. Pasien dimasukkan kedalam area magnet.Pengaturan sekuens dan parameter Pemeriksaan dilakukan dengan sekuens Axial T2, Sagital T2, Coronal T2, Axial T1, Sagital T1,Coronal T1, Axial DWI, Axial T2*GRE. Setelah sekuens tersebut kemudian dilakukan injeksi media kontras Gadolinium (Gd) dengan dosis $0,02 \mathrm{mmol} / \mathrm{Kg} \mathrm{BB}$

Pemeriksaan dilanjutkan dengan sekuens T1WI FSE menggunakan Fat Saturasi dan tanpa menggunakan Fat saturasi dilakukan pada obyek Kepala 10 pasien, dengan cara masing - masing pasien dilakukan scanning dengan sekuenss T1WI FSE menggunakan Fat saturasi kemudian dilanjutkan dengan scanning sekuens T1WI FSE tanpa menggunakan Fat saturasi. Pengaturan parameter yang dilakukan pada penelitian ini sudah merupakan program yang ada pada pesawat MRI GE 1,5 Tesla yang menghasilkan kualitas citra terbaik.Setelah memperoleh hasil gambaran MRI kepala potongan axial sekuens T1WI FSE menggunakan Fat saturasi dan tanpa menggunakan Fat saturasi, kemudian dipilih irisan Axial yang akan dicetak pada film.

\section{Analisis Data}

Dalam penelitian ini analisis deskriptik yang dilakukan dengan merangkum hasil penilaian dari masing - masing responden, kemudian dari rangkuman hasil penilaian tersebut dibuat rata - rata hasil penilaian tiap organ yang diteliti, kemudian dideskripsikan dalam bentuk tabel. analisis statistik ini ditetapkan tingkat kepercayaan (level of significance) dengan nilai $\alpha=0,05$. Ho ditolak apabila $p$ value $<0,05$, yang berarti ada perbedaan informasi anatomi kepala pada pemeriksaan MRI kepala post media kontras dengan sekuen T1WI FSE dengan fat saturasi dan tanpa fat saturasi. Ho diterima apabila $\mathrm{p}$ value $>0,05$, yang berarti tidak ada perbedaan informasi anatomi kepala pada pemeriksaan MRI kepala post media kontras dengan sekuen T1WI FSE dengan fat Saturasi dan tanpa fat Saturasi. 
HASIL

Deskripsi lokasi penelitian ini dilakukan di Instalasi Radiologi Rumah Sakit Panti Rapih Yogyakarta pada bulan September - Desember 2016.

Deskripsi Sampel dalam penelitian ini jumlah sampel yang digunakan sebanyak 10 orang dengan rentang usia 20-60 tahun. Dari 10 sampel tersebut terdiri dari laki-laki 6 orang dan perempuan 4 orang. Sampel datang ke radiologi dengn permintaan MRI kepala dengan kontras.

Hasil Penilaian Informasi Anatomi Sinus Maksilaris Fat Sat Dan Non Fat Sat.

Berdasarkan hasil penilaian ketiga responden terhadap 10 citra dengan Fat Sat dan 10 citra Non Fat Sat pada sinus maksilaris dapat dilihat pada tabel 1 berikut ini :

Tabel 1. Hasil penilaian untuk sinus maksilaris

\begin{tabular}{|c|c|c|c|c|c|c|c|c|c|c|c|}
\hline \multirow{2}{*}{ Perlakuan } & \multicolumn{10}{|c|}{ Nilai Infomasi Anatomi } & \multirow{2}{*}{ Total } \\
\hline & 1 & 2 & 3 & 4 & 5 & 6 & 7 & 8 & 9 & 10 & \\
\hline Fat Sat & 6 & 6 & 6 & 7 & 5 & 5 & 5 & 6 & 4 & 6 & 56 \\
\hline $\begin{array}{l}\text { Non Fat } \\
\text { Sat }\end{array}$ & 9 & 9 & 9 & 8 & 9 & 9 & 9 & 9 & 8 & 9 & 88 \\
\hline
\end{tabular}

Berdasarkan Tabel 1. data tersebut menunjukkan bahwa dari penilaian ketiga responden terhadap 10 citra Fat Sat dan 10 citra Non Fat Sat pada sinus maksilaris diperoleh hasil menggunakan non Fat Sat dengan kriteria jelas ( 88 ) dibandingkan Fat Sat dengan kriteria cukup jelas ( 56 )

Hasil Penilaian informasi Anatomi Orbita Fat Sat dan Non Fat Sat

Hasil penilaian ketiga responden terhadap 10 citra Fat Sat dan 10 citra Non Fat Sat pada orbita dapat dilihat pada tabel 2 berikut ini :

Tabel 2. Hasil penilaian untuk orbita

\begin{tabular}{cccccccccccc}
\hline \multirow{2}{*}{ Perlakuan } & \multicolumn{1}{c}{ Nilai Infomasi Anatomi } & & Total \\
\cline { 2 - 11 } & 1 & 2 & 3 & 4 & 5 & 6 & 7 & 8 & 9 & 10 & \\
\hline Fat Sat & 6 & 6 & 6 & 6 & 5 & 7 & 6 & 6 & 8 & 5 & 61 \\
Non Fat & 9 & 8 & 7 & 7 & 5 & 7 & 7 & 7 & 7 & 9 & 73 \\
Sat & & & & 7 & & & & & & & \\
\hline
\end{tabular}

Berdasarkan Tabel 2. data tersebut menunjukkan bahwa dari penilaian ketiga responden terhadap 10 citra Fat Sat dan 10 citra Non Fat Sat pada orbita diperoleh hasil menggunakan non Fat Sat dengan kriteria jelas ( 73 ) dibandingkan Fat Sat dengan kriteria cukup jelas ( 61 ).

Hasil Penilaian Informasi Anatomi Basis Cranii Fat Sat dan Non Fat Sat

Berdasarkan hasil penilaian ketiga responden terhadap 10 citra Fat Sat dan 10 citra Non Fat Sat pada Basis Cranii dapat dilihat pada tabel 3. Berdasarkan Tabel 3. data tersebut menunjukkan bahwa dari penilaian ketiga responden terhadap 10 citra Fat Sat dan 10 citra Non Fat Sat pada Basis Cranii diperoleh hasil menggunakan non Fat Sat dengan kriteria jelas ( 72 ) dibandingkan Fat Sat dengan kriteria kurang jelas (49).
Tabel 3. Hasil penilaian untuk Basis Cranii

\begin{tabular}{|c|c|c|c|c|c|c|c|c|c|c|c|}
\hline \multirow{2}{*}{ Perlakuan } & \multicolumn{10}{|c|}{ Nilai Infomasi Anatomi } & \multirow[t]{2}{*}{ Total } \\
\hline & 1 & 2 & 3 & 4 & 5 & 6 & 7 & 8 & 9 & 10 & \\
\hline Fat Sat & 6 & 5 & 5 & 4 & 5 & 5 & 5 & 4 & 4 & 6 & 49 \\
\hline $\begin{array}{c}\text { Non Fat } \\
\text { Sat }\end{array}$ & 8 & 7 & 7 & 7 & 7 & 7 & 8 & 6 & 7 & 8 & 72 \\
\hline
\end{tabular}

\section{Hasil Penilaian informasi Anatomi Cerebro Spinal Fluid(CSF) Fat sat dan Non Fat Sat}

Berdasarkan hasil penilaian ketiga responden terhadap 10 citra Fat Sat dan 10 citra Non Fat Sat pada Cerebro Spinal Fluid (CSF) dapat dilihat pada tabel 4 berikut ini.

Tabel 4. Hasil penilaian untuk Cerebro Spinal Fluid (CSF)

\begin{tabular}{cccccccccccc}
\hline \multirow{2}{*}{ Perlakuan } & \multicolumn{1}{c}{ Nilai Infomasi Anatomi } & & Total \\
\cline { 2 - 11 } & 1 & 2 & 3 & 4 & 5 & 6 & 7 & 8 & 9 & 10 & \\
\hline Fat Sat & 6 & 7 & 7 & 7 & 8 & 6 & 7 & 6 & 7 & 6 & 67 \\
Non Fat & 9 & 9 & 9 & 9 & 9 & 9 & 9 & 8 & 9 & 8 & 88 \\
$\quad$ Sat & & & &
\end{tabular}

Berdasarkan Tabel 4 data tersebut menunjukkan bahwa dari penilaian ketiga responden terhadap 10 citra Fat Sat dan 10 citra Non Fat Sat pada Cerebro Spinal Fluid (CSF) diperoleh hasil menggunakan non Fat Sat dengan kriteria jelas ( 88 ) dibandingkan Fat Sat dengan kriteria cukup jelas ( 67 ).

Hasil Penilaian informasi Anatomi Sulcus Gyrus Fat Sat dan Non Fat Sat.

Berdasarkan hasil penilaian ketiga responden terhadap 10 citra Fat Sat dan 10 citra Non Fat Sat pada Sulcus Gyrus dapat dilihat pada tabel 5 berikut ini

Tabel 5. Hasil penilaian untuk Sulcus Gyrus

\begin{tabular}{cccccccccccc}
\hline \multirow{2}{*}{ Perlakuan } & \multicolumn{10}{c}{ Nilai Infomasi Anatomi } & Total \\
\cline { 2 - 9 } & $\mathbf{1}$ & $\mathbf{2}$ & $\mathbf{3}$ & $\mathbf{4}$ & $\mathbf{5}$ & $\mathbf{6}$ & $\mathbf{7}$ & $\mathbf{8}$ & $\mathbf{9}$ & $\mathbf{1 0}$ & \\
\hline Fat Sat & 8 & 8 & 7 & 8 & 7 & 8 & 7 & 6 & 8 & 8 & $\mathbf{7 5}$ \\
$\begin{array}{c}\text { Non Fat } \\
\text { Sat }\end{array}$ & 7 & 6 & 7 & 7 & 8 & 8 & 8 & 8 & 8 & 8 & $\mathbf{7 5}$ \\
\hline
\end{tabular}

Berdasarkan Tabel 5 data tersebut menunjukkan bahwa dari penilaian ketiga responden terhadap 10 citra Fat Sat dan 10 citra Non Fat Sat pada Sulcus Gyrus diperoleh hasil menggunakan Non Fat Sat dengan kriteria jelas (75) dan Fat Sat dengan kriteria jelas (75).

\section{Hasil Penilaian informasi Anatomi Cutis Fat sat dan Non Fat Sat}

Berdasarkan hasil penilaian ketiga responden terhadap 10 citra Fat Sat dan 10 citra Non Fat Sat pada cutis dapat dilihat pada tabel 6. Berdasarkan Tabel 6 data tersebut menunjukkan bahwa dari penilaian ketiga responden terhadap 10 citra Fat Sat dan 10 citra Non Fat Sat pada Cutis diperoleh hasil menggunakan Non Fat Sat dengan kriteria jelas ( 72 ) dibandingkan Fat Sat dengan kriteria cukup jelas ( 69 ). 
Tabel 6 Hasil penilaian untuk Cutis

\begin{tabular}{cccccccccccc}
\hline & \multicolumn{1}{c}{ Nilai Infomasi Anatomi } & \multirow{2}{*}{ Total } \\
\cline { 2 - 9 } Perlakuan & 1 & 2 & 3 & 4 & 5 & 6 & 7 & 8 & 9 & 10 & \\
\hline Fat Sat & 7 & 8 & 6 & 7 & 7 & 7 & 7 & 7 & 6 & 7 & 69 \\
Non Fat & 8 & 8 & 6 & 7 & 7 & 7 & 7 & 7 & 7 & 8 & 72 \\
Sat & & & & & & & & \\
\hline
\end{tabular}

Hasil Penilaian informasi Anatomi Sub Cutis Fat Sat dan Non Fat Sat

Berdasarkan hasil penilaian ketiga responden terhadap 10 citra Fat Sat dan 10 citra Non Fat Sat pada Sub Cutis dapat dilihat pada tabel 7 berikut ini:

Tabel 7. Hasil penilaian untuk Sub Cutis

\begin{tabular}{ccccccccccccc}
\hline & \multicolumn{1}{c}{ Nilai Infomasi Anatomi } & & Total \\
\cline { 2 - 11 } Perlakuan & 1 & 2 & 3 & 4 & 5 & 6 & 7 & 8 & 9 & 10 & \\
\hline Fat Sat & 7 & 8 & 7 & 7 & 7 & 7 & 7 & 8 & 6 & 7 & 71 \\
$\begin{array}{c}\text { Non Fat } \\
\text { Sat }\end{array}$ & 8 & 8 & 6 & 8 & 8 & 8 & 7 & 7 & 8 & 8 & 76 \\
\hline
\end{tabular}

Berdasarkan Tabel 7. data tersebut menunjukkan bahwa dari penilaian ketiga responden terhadap 10 citra Fat Sat dan 10 Citra Non Fat Sat pada Sub Cutis diperoleh hasil menggunakan Non Fat Sat dengan kriteria jelas (76) dibandingkan Fat Sat dengan kriteria jelas (71).

Hasil Penilaian informasi Anatomi Lesi Patologi Fat Sat dan Non Fat Sat.

Berdasarkan hasil penilaian ketiga responden terhadap 10 citra Fat Sat dan 10 citra Non Fat Sat pada Lesi Patologi dapat dilihat pada tabel 8 berikut ini:

Tabel 8. Hasil penilaian untuk Lesi Patologi

\begin{tabular}{cccccccccccc}
\hline & \multicolumn{1}{c}{ Nilai Infomasi Anatomi } & & Total \\
\cline { 2 - 7 } & 1 & 2 & 3 & 4 & 5 & 6 & 7 & 8 & 9 & 10 & \\
\hline Fat Sat & 7 & 9 & 7 & 9 & 7 & 8 & 7 & 9 & 8 & 7 & 78 \\
$\begin{array}{c}\text { Non Fat } \\
\text { Sat }\end{array}$ & 7 & 7 & 4 & 7 & 5 & 6 & 5 & 6 & 5 & 5 & 57 \\
\hline
\end{tabular}

Berdasarkan Tabel 8. data tersebut menunjukkan bahwa dari penilaian ketiga responden terhadap 10 citra Fat Sat dan 10 citra Non Fat Sat pada Sub Cutis diperoleh hasil menggunakan Fat Sat dengan kriteria jelas (78) dibandingkan Non Fat Sat dengan kriteria cukup jelas (57)

Perbedaan informasi anatomi penggunaan sekuens T1WI dengan Fat Saturasi Dan Non Fat Saturasi.

Berdasarkan penilaian secara umum yaitu dengan membandingkan total responden antara penggunaan Fat Saturasi Dan Non Fat Saturasi menunjukkan perbedaan Informasi anatomi dapat dilihat pada tabel 9. Berdasarkan Hasil Penilaian pada Tabel 9 bisa dilihat bahwa nilai dari tiap organ berbeda beda setelah dilakukan dua perlakuan kecuali organ sulcus gyrus yang menunjukkan nilai yang sama dalam kriteria jelas (75). Dimana nilai dari sinus maksilaris dengan
Fat Saturasi masuk dalam kriteria cukup jelas (56) dan Non Fat saturasi dengan kriteria jelas (88), nilai dari Orbita dengan Fat Saturasi masuk dalam kriteria cukup jelas (61) dan Non Fat Saturasi dengan kriteria jelas (73).

Tabel 9. Hasil Penilaian Informasi Anatomi sekuens T1 WI dengan Fat Saturasi dan Non Fat Saturasi

\begin{tabular}{|c|c|c|c|c|c|c|c|c|}
\hline $\begin{array}{c}\text { Perlaku } \\
\text { an }\end{array}$ & $\begin{array}{c}\text { Sinu } \\
\mathrm{S}\end{array}$ & $\begin{array}{c}\text { Orbit } \\
\mathrm{a}\end{array}$ & $\begin{array}{c}\text { Basi } \\
\mathrm{s}\end{array}$ & $\begin{array}{c}\text { CS } \\
F\end{array}$ & $\begin{array}{c}\text { Sulg } \\
\mathrm{y}\end{array}$ & $\begin{array}{c}\text { Cuti } \\
\text { s }\end{array}$ & $\begin{array}{c}\text { Subc } \\
\mathrm{u}\end{array}$ & $\begin{array}{c}\text { Les } \\
\mathrm{i}\end{array}$ \\
\hline Fat Sat & 56 & 61 & 49 & 67 & 75 & 69 & 71 & 78 \\
\hline $\begin{array}{c}\text { Non Fat } \\
\text { Sat }\end{array}$ & 88 & 73 & 72 & 88 & 75 & 72 & 76 & 57 \\
\hline
\end{tabular}

Nilai Dari Basis Cranii dengan Fat Saturasi masuk dalam kriteria tidak jelas (49) dan Non Fat Saturasi dengan kriteria jelas (72), Nilai Dari Cerebro Spinal Fluid (CSF) dengan Fat Saturasi masuk dalam kriteria cukup jelas (67) dan Non Fat Saturasi dengan kriteria jelas (88), nilai dari Sulcus Gyrus dengan Fat saturasi masuk dalam kriteria jelas (75) dan Non Fat Saturasi dengan kriteria jelas (75), Nilai Dari Cutis dengan Fat Saturasi masuk dalam kriteria cukup jelas (69) dan Non Fat Saturasi dengan kriteria jelas (72), Nilai Dari Sub Cutis dengan Fat Saturasi masuk dalam kriteria jelas (71) dan Non Fat Saturasi dengan kriteria jelas (76), Nilai Dari Lesi Patologi dengan Fat Saturasi masuk dalam kriteria jelas (78) dan Non Fat Saturasi dengan kriteria cukup jelas (57).

\section{Analisis Statistik dengan Metode Wilcoxon}

Berdasarkan hasil penelitian perbedaan informasi anatomi kepala pada pemeriksaan MRI kepala post media kontras T1WI FSE dengan Fat Saturasi dan Non Fat Saturasi disajikan pada tabel 10 sebagai berikut:

Tabel 10 Perbedaan Informasi Anatomi antara perlakuan Fat Saturasi dan Non Fat Saturasi

\begin{tabular}{ccccc}
\hline Perlakuan & N & Std. Deviasi & $\begin{array}{c}\text { Mean } \\
\text { Rank }\end{array}$ & $\mathrm{p}$ \\
\hline Fat Sat & 8 & 9,809 & 4,50 & \multirow{2}{*}{0,108} \\
Non Fat Sat & 8 & 9,891 & 3,92 & \\
\hline
\end{tabular}

Berdasarkan tabel 10 diperoleh tidak ada perbedaan informasi anatomi kepala pada pemeriksaan MRI kepala post media kontras T1WI FSE dengan Fat Saturasi dan tanpa Fat Saturasi $(\mathrm{p}>0,05)$.

\section{DISKUSI}

Gambaran sinus maksilaris dari kedua perlakuan dengan analisa deskriptif menunjukkan hasil bahwa dengan Fat Saturasi diperoleh nilai 56 yang masuk dalam kriteria cukup jelas dan pada Non Fat Saturasi diperoleh nilai 88 yang masuk kriteria jelas. Hal ini sesuai dengan westbrook (1999) pulsa fat suppression hanya digunakan jika diaplikasikan pada jaringan (khususnya lemak), dan tidak efektif jika diaplikasikan pada udara. Dimana sinus maksilaris merupakan bagian dari kepala yang terdiri dari udara, mukosa, dan tulang, sehingga pengaplikasian Fat Saturasi akan mengurangi batas antara 
rongga dan tulang karena lemak pada lapisan mukosa sinus tersupresi oleh fat saturasi.

Gambaran Orbita dari kedua perlakuan dengan analisa deskriptif menunjukkan hasil bahwa dengan Fat Saturasi diperoleh niai 61 yang masuk kriteria cukup jelas dan Non Fat Saturasi diperoleh nilai 73 yang masuk kriteria jelas. Fat saturasi pada orbita dapat mengurangi sinyal lemak disekitar optik nerve namun tidak terlalu berpengaruh terhadap organ orbita. Menurut Sirin (2012) berguna untuk menilai laminar optic nerve dan Non Fat Saturasi untuk menilai adanya invasi pada choroidal.

Gambaran Basis Cranii dari kedua perlakuan dengan analisa deskriptif menunjukan hasil bahwa dengan Fat Saturasi diperoleh nilai 49 yang masuk kriteria kurang jelas dan Non Fat Saturasi diperoleh nilai 72 yang masuk kriteria jelas. Gambaran basis cranii hampir sama seperti sinus maksilaris, dimana basis cranii tersusun dari tulang yang dikelilingi lemak, sehingga penggunaan fat saturasi tidak akan mempengaruhi gambaran basis cranii karena fat saturasi hanya efektif pada lemak. Hal ini sesuai dengan Westbrook (1999) pulsa fat suppression hanya digunakan jika diaplikasikan pada jaringan (khususnya lemak). Namun Fat saturasi akan mensupresi sinyal lemak di sekitar basis cranii sehingga akan tampak lebih redup.

Gambaran Cerebro Spinal Fluid (CSF) dari kedua perlakuan dengan analisa deskriptif menunjukan hasil bahwa dengan Fat Saturasi diperoleh nilai 67 yang masuk kriteria cukup jelas dan Non Fat Saturasi diperoleh nilai 88 yang masuk kriteria jelas. Cerebro Spinal Fluid (CSF) memiliki konsentrasi air yang tinggi sehingga dalam pembobotan T1 akan tampak hipointense, akan tampak tegas batas dengan gray matter pada perlakuan T1WI biasa tanpa fat saturasi (guledgud,2015).

Gambaran Sulcus Gyrus dari kedua perlakuan dengan analisa deskriptif menunjukkan hasil bahwa dengan Fat saturasi diperoleh nilai 75 yang masuk kriteria jelas dan Non Fat Saturasi diperoleh nilai 75 yang masuk kriteria jelas. Sulcus Gyrus mempunyai nilai yang sama dikarenakan tidak terlalu terpengaruh oleh penggunaan Fat saturasi.

Gambaran Cutis dari kedua perlakuan dengan analisa deskriptif menunjukkan hasil bahwa dengan Fat Saturasi diperoleh 69 yang masuk kriteria cukup jelas dan Non Fat Saturasi diperoleh nilai 72 yang masuk kriteria jelas, sedangkan gambaran Sub Cutis dengan Fat Saturasi diperoleh nilai 71 yang masuk kriteria jelas dan Non Fat Saturasi diperoleh nilai 76 yang masuk kriteria jelas

Gambaran Lesi Patologi dari kedua perlakuan dengan analisa deskriptif menunjukan hasil bahwa dengan Fat Saturasi diperoleh nilai 78 yang masuk dalam kriteria jelas dan Non Fat Saturasi diperoleh nilai 57 yang masuk kriteria cukup jelas. Hal ini sesuai dengan penelitian Robert,dkk (1992) bahwa tumor, metastase maupun peradangan akan tampak isointense pada T1 enhance kontras. Sehingga ditambahkan sekuens fat saturasi bertujuan untuk meningkatkan intensitas dan homogenitas contrast enhancement serta menekan intensitas sinyal pada epidural fat.
Menurut pendapat peneliti dari hasil deskriptik menunjukkan bahwa informasi anatomi kepala pada pemeriksaan MRI kepala post media kontras dengan fat saturasi menunjukkan organ yang masuk kriteria jelas adalah sulcus gyrus dan lesi patologi sedangkan pada perlakuan tanpa Fat saturasi organ yang masuk kriteria jelas adalah sinus maksilaris, orbita, basis cranii, Cerebro Spinal Fluid (CSF), sulcus gyrus, cutis dan sub cutis. Hal ini karena dalam pemeriksaan MRI kepala post media kontras dengan T1WI non fat saturasi jaringan lemak akan tampak hiperintenses. Diantara jaringan lunak yang mengandung lemak seperti pada sinus maksilaris, orbita, basis cranii, cutis dan sub cutis akan tampak hiperintenses sehingga menyebabkan citra anatominya tampak jelas. Sedangkan pada TIWI fat saturasi jaringan lemak akan tampak hipo intense. Pada pemeriksaan MRI kepala post media kontras T1 WI fat saturasi biasanya digunakan untuk membuktikan lesi tersebut mengandung lemak. Fat Saturasi digunakan untuk memperjelas lesi diantara jaringan lemak disekitarnya. Dengan Fat Saturasi biasanya lesi yang enhanced menjadi putih dan menonjol diantara lemak yang relatif hitam. Dari penjelasan tersebut bisa ditarik kesimpulan T1 WI FSE post media kontras dengan Fat Saturasi digunakan untuk menilai lesi patologi sedangkan non fat saturasi digunakan untuk menilai informasi anatominya.

\section{SIMPULAN}

Dari hasil analisa statistik terlihat bahwa tidak ada perbedaan informasi anatomi yang signifikan antara penggunaan Fat Saturasi (Fat Sat) dan Non Fat Saturasi (Non Fat Sat) berdasarkan uji Wilcoxon yang telah dilakukan dengan nilai $p>0,05$

Dari hasil deskriptik menunjukkan informasi anatomi penggunaan Fat Saturasi (Fat Sat) yang dinilai jelas adalah sulcus gyrus dan lesi patologi, sedangkan Non Fat Saturasi (Non Fat Sat) yang dinilai jelas adalah sinus maksilaris, orbita, basis cranii, cerebrospinal fluid (CSF), sulcus gyrus, cutis, dan sub cutis.

Berdasarkan pertimbangan hasil penelitian dan pembahasan pada pemeriksaan MRI kepala post media kontras sebaiknya menggunakan T1 WI FSE tanpa fat saturasi dan jika diperlukan baru ditambahkan dengan T1 WI FSE fat saturasi

\section{DAFTAR PUSTAKA}

Agur, Anne M.R. dan Dalley, Arthur F. 2009. Grant's Atlas of Anatomy. Lippincott Williams \& Wilkins : Philadelphia.

Al- Saeed, Moh Ismail, Reji Athyl, Mehraj Sheikh. 2011. Fat Saturated Post Gadolinium T1 Imaging of Brain in multiple sclerosis. Kuwait.

Brant, Zawadzki. 2002. Spine, Top 100 Diagnoses. Amirsys Inc : Salt Lake City, Utah.

Brown, M.A dan Richard C. Semelka. 2003. MRI Basic Principle and Applications, Third Edition. John Wiley and Sons Inc : New Jersey.

Edelman, Robert R. 2009. Fast Spin Echo. Softways : Magnetic Resonance Technology Information Portal: Wisconsin.

Guledgud, Patil, Shankar, Dhespande, Raman. 2015. Magnetic Resonance Imaging In Head And Neck Radiodiagnosis, Journal Of Medicine, Radiology, Pathology \& Surgery. Karnataka India. 
Kuperman, Vadim. 2000. Magnetic Resonance Imaging Physical Principles and Applications. Academic Press, A Harcourt Science and Technology Company : New York.

Robert,dkk. 1992. Diseases of the lumbar spine : Findings on Fat Suppression MR imaging. AJR online diakses 3 januari 2017.

Sirin, et al. 2012. Diagnostic image quality of gadolinium enhanced T1 Weighted MRI with and without fat saturation in children with retinoblastoma. Springer - Verlag: Berlin.

Westbrook, Chaterine and Kaut, Carolyne. 1998. MRI in Practice, Third Edition. Blackwell Science Ltd : United Kingdom.

Westbrook, Catherine. 2008. Handbook of MRI technique. Blackwell Science Ltd. : United Kingdom.

Westbrook, Chaterine. 2002. MRI at a Glance. Blackwell Science Ltd : United Kingdom.

Woodward, Peggy and Freimarck, Roger. 2000. MRI for Technologists Second edition. McGraw-Hill, Inc : New York, USA.

Woodward, Peggy and Orrison, William W. 1997. MRI Optimization ; A Hands-on Approach. Mc. Graw Hill : New York. 